\title{
The Time Interval Between the Start of Anti-Leprosy Treatment and the Development of Reactions in Borderline Patients
}

\author{
B. NAAFS AND H. W. WHEATE \\ All Africa Leprosy and Rehabilitation Training Centre, P.O. Box 165, Addis Ababa, Ethiopia
}

\begin{abstract}
One hundred patients who developed a reversal reaction were analysed with respect to the time lapse between the start of treatment and the start of the reaction.

It was found that in nearly all cases BT and BB patients developed reaction in the first half year of treatment. For BL patients such an obvious relationship could not be found.

The authors express the opinion that the reversal reaction is a natural occurrence in the course of untreated borderline leprosy and that although sulphone treatment may accelerate the reaction it certainly does not cause it.
\end{abstract}

\section{Introduction}

The mechanism of reaction in borderline leprosy - known as "reversal reaction"-is not yet completely understood; but it is thought to be related to an enhanced cell mediated immunity (CMI) against M. leprae antigen (Godal et al., 1973). Plasma factors may be involved (Bjune and Barnetson, 1976). However it is generally accepted that early and adequate treatment can prevent nerve damage in many cases. Some authors hold sulphone treatment responsible for this nerve damage and therefore favour leprosy treatment with low doses of sulphone (Jopling, 1974; Leiker, 1976). When a reaction occurs discontinuance of the sulphones is considered (Sixth International Congress of Leprosy, Madrid, 1953; Wheate, 1962).

Early papers concerning sulphone treatment and the occurrence of reactions are very confusing. Some authors claim that reactions are caused by sulphones (Cochrane, 1949); others, however, noticed subsiding of the reaction after starting sulphone treatment (De Souza Lima, 1948). Although many of the authors were good clinicians and keen observers the issue continued to be controversial for many years.

Recently however some authors have shown that DDS on its own can reverse nerve damage when no reaction occurs (Naafs et al., 1976). Prasad (1971) showed in a controlled study that tuberculoid patients on $200 \mathrm{mg}$ DDS 6 days a week from the start of treatment did better than a group of patients receiving more conventional doses of DDS (starting with $25 \mathrm{mg}$ twice weekly, 
increasing to $300 \mathrm{mg}$ twice weekly after 4 months). Barnetson et al. (1976) showed that in a group of borderline patients receiving DDS $50 \mathrm{mg}$ daily there were significantly less reactions than in a group of borderline patients receiving only $5 \mathrm{mg}$ daily.

In this article we analyse the data of 100 borderline patients who developed a reaction, with particular reference to the time interval between the start of treatment and the start of reaction.

\section{Patients and Methods}

The patients in this study attended the Out-patient Department of the Addis Ababa Leprosy Hospital. The majority were self-reporting. Clinical classification was according to the Ridley-Jopling 5-point scale (Ridley and Jopling, 1966) and in the majority of cases the clinical classification was confirmed histologically. Patients were considered to be in reaction when prednisolone was needed to prevent further nerve damage. Nerve damage was assessed by means of voluntary muscle testing, sensory testing and motor conduction velocity measurements. In many cases the presence of reaction was confirmed histologically. In those patients in whom a lymphocyte transformation test (LTT) was done $( \pm 30 \%)$ the LTT was markedly raised indicating an enhanced CMI.

\section{Results}

Table 1 shows the distribution according to classification of the 100 patients analysed (50 BT, $13 \mathrm{BB}$ and $37 \mathrm{BL}$ patients) and the time lapse between the start of treatment and the moment of established reaction.

TABLE 1

\begin{tabular}{lcccccccc}
\hline & $\begin{array}{c}\text { Total } \\
\text { number }\end{array}$ & $\begin{array}{c}\text { Before } \\
\text { treatment }\end{array}$ & $\begin{array}{c}<1 \\
\text { month }\end{array}$ & $\begin{array}{c}<3 \\
\text { months }\end{array}$ & $\begin{array}{c}<6 \\
\text { months }\end{array}$ & $\begin{array}{c}<1 \\
\text { year }\end{array}$ & $\begin{array}{c}<2 \\
\text { years }\end{array}$ & $\begin{array}{c}>2 \\
\text { years }\end{array}$ \\
\hline BT & 50 & 30 & 5 & 10 & 4 & - & 1 & - \\
BB & 13 & 9 & 2 & 1 & - & - & 1 & - \\
BL & 37 & 12 & 2 & 2 & 1 & 8 & 6 & 6 \\
\hline
\end{tabular}

Distribution of borderline patients who developed a reaction according to time lapse between start of treatment and start of reversal reaction.

It will be seen that many of the patients in the series presented themselves at the clinic already in reaction: $60 \%$ of the BT patients and $70 \%$ of the BB patients. The remaining patients in these 2 classifications developed reactions during the first half year of treatment, except 2 who developed their reaction after 2 years. In these patients, biopsy of the dorsal cutaneous branch of the radial nerve still showed fragments of bacilli, although both the initial skin smear and the skin biopsy had been negative for acid-fast bacilli.

BL patients developed reactions over a much longer period but, even so, 
$30 \%$ of them reported themselves for treatment already in reaction. In about $30 \%$ of the patients in our study urinary estimation of DDS was carried out before starting treatment, with negative results in all. This test therefore provided no evidence of previous treatment.

\section{Discussion}

Many leprologists believe that a reversal reaction is produced by antileprosy treatment (Jopling, 1974; Leiker, 1976; Carayon, 1976) and when a patient presents himself in reaction claiming to have received no previous treatment, some go so far as to suspect that he has bought DDS on the black market. However, our series indicates that reversal reaction is a natural occurrence in the course of borderline leprosy. More than $50 \%$ of our cases had already developed reaction before starting antileprosy treatment. Further evidence for the natural occurrence of reversal reaction in untreated cases is the great number of new patients who report themselves for treatment with already established nerve damage (Schneider, 1975).

In a clinic in which new cases are usually self reporting, as in ours, many present with early signs of reaction such as hyperactive oedematous skin patches, rheumatic pains, tingling paraesthesiae or recent loss of sensation. It is, in fact these reactional signs which bring these patients to ask for treatment.

After starting dapsone treatment $(50 \mathrm{mg}$ daily) we observed that in the majority of cases these signs settled within 3-6 months. This is in accordance with earlier observations of Lowe (1950) and Cochrane (1964). De Souza Lima (1949) and Lowe (1950) reported that patients who go into reaction usually do so within the first months of dapsone treatment. Our series shows the same trend.

Barnetson et al. (1976) showed that a daily dosage of DDS of $50 \mathrm{mg}$ settles reactional signs in the majority of cases, and Haile Gebre Selassie and Pearson (1977) showed that a reaction could effectively be treated with DDS in a dose of $200 \mathrm{mg}$ daily; in many cases no prednisolone was needed. This may be due to a supposed immunosuppressive effect of dapsone (Beiguelman and Pisani, 1974; Barnetson et al., 1976).

That a reaction can happen in untreated cases is understandable, when we assume that multiplication of $M$. leprae leads to an increase of $M$. leprae antigens, thus bringing the antigen level above the "threshold" needed to give a full blown reversal reaction.

However, dapsone treatment which prevents the multiplication of the bacilli does not prevent a reaction in all cases. This may be explained by assuming that the antigens responsible for reversal reaction are released from dead and dying bacilli and not, or to a lesser extent, from live bacilli. Some workers are at present investigating this hypothesis (Harboe, 1977). During the first half year of treatment, expecially in "active" cases, the number of dead bacilli may increase and the total antigen load may reach the threshold level and a reaction occurs. The observation that Rifampicin increases the number of reversal reactions (Steenbergen and Pfaltzgraff, 1975) can be explained by the fact that Rifampicin is a rapid killer, thus increasing the number of dead and dying bacilli so quickly that the immunosuppressive eff ect is inadequate. 
In the BL group it appears more difficult to find a time relationship between the start of treatment and the reaction. In this group there is an enormous amount of antigens; it takes the body a long time (years) to dispose of them and the risk of a reversal reaction is prolonged.

This small paper may contribute to the following conclusions:

(1) Reversal reaction belongs to the normal sequence in untreated BT and BB patients. DDS treatment is not directly responsible for this phenomenon. It may accelerate the process but certainly does not cause it.

(2) Borderline patients should be under good supervision especially during the first half year of treatment. For BT and BB patients the risk of reaction after this period is negligible and if it does occur care should be taken to check the initial classification and to exclude DDS resistance.

\section{Acknowledgements}

Our thanks are due to Dr Barnetson, Dr Pearson and Dr Ridley, who did the histology, the staff of the Armauer Hansen Research Institute who did the LTT's and to our colleagues the physicians of ALERT, who were always willing to help and to discuss findings and theories.

\section{Resume}

Une groupe de cente malades lèpreux en réaction d'inversion a été suivée pour voir si le début de la réaction a un rapport quelconque avec le début du traitement.

Les malades $\mathrm{BT}$ et $\mathrm{BB}$ ont presque tous été en réaction d'inversion dans les premiers six mois du traitement. Une relation aussi étroite n'a pu être établie pour les cas BL. Les auteurs sont d'avis que la réaction d'inversion est un phenomène normal dans la lèpre borderline non traitée. Ils pensent que, si les sulphones peuvent précipiter cette réaction, ils n'en sont pas la cause.

\section{References}

Barnetson, R. St C., Pearson, J. M. H. and Rees, R. J. W. (1976). Evidence for prevention of borderline leprosy reactions by dapsone. Lancet 11,1171 .

Beiguelman, B. and Pisani, R. C. B. (1974). Effect of DDS on phytohemagglutinin-induced lymphocyte transf ormation. Int. J.Lepr. 42, 412.

Bjune, G. and Barnetson, R. St C. (1976). Plasma factors in delayed-type hypersensitivity. Augmentation of lymphocyte responses in borderline leprosy reactions. Clin. exp. Immunol. 26, 397.

Carayon, A. (1976). Personal communication.

Cochrane, R. G. (1949). General principle in the treatment of leprosy with particular reference to the sulphones. Lepr. India $21,83$.

Cochrane, R. G. (1964). In "Leprosy in Theory and Practice", 2nd edit. p. 283. John Wright and Sons Ltd, Bristol.

Godal, T., Myrvang, B., Samuel, Dorothy R., Ross, W. F. and Løfgren, Monica. (1973). Mechanism of "reactions" in borderline tuberculoid (BT) leprosy. A preliminary report. Acta path. microbiol. Scand., Sect. A., Suppl. 236, 45.

Haile Gebre Selassie and Pearson, J. M. H. (1977). Paper at the Thirteenth Annual Conference of the Ethiopian Medical Association.

Harboe, M. (1977). Personal communication.

Jopling, W. H. (1974). Any questions: dapsone in leprosy. Tropical Doctor 4, 140.

Leiker, D. L. (1976). Personal communication.

Lowe, J. (1950). The sulphone treatment of tuberculoid leprosy. Int. J. Lepr. 18, 457.

Naafs, B., Pearson, J. M. H. and Baar, A. J. M. (1976). A follow-up study of nerve lesions in leprosy during and after reaction using motor nerve conduction velocity. Int. J. Lepr. 44, 188. 
Prasad, B. N. (1971). Trial of high dosages of dapsone in the treatment of tuberculoid leprosy. Lepr. Rev. 42, 118.

Ridley, D. S. and Jopling, W. H. (1966). Classification of leprosy according to immunity. A five group system. Int. J. Lepr. 34, 255.

Schneider, H. (1975). Leprosy and Other Health Problems in Hararghe, Ethiopia. Thesis, University of Groningen, The Netherlands.

Sixth International Congress of Leprosy (Madrid). (1953). Sulphone treatment. Int.J. Lepr. 21, 516.

de Souza Lima, L. (1948). Present state of sulphone therapy at Padre Bento Sanatorium. Int.J. Lepr. 16, 127.

de Souza Lima, L. and de Souza, P. R. (1949). Pseudoexacerbation of leprosy due to diaminodiphenylsulphones. Int. J.Lepr. $17,19$.

Steenbergen, G. J. and Pfaltzgraff, R. E. (1975). Treatment of neuritis in borderline leprosy with Rif ampicin and corticosteroids - a pilot trial. Le pr. Rev. 46, 115.

Wheate, H. W. (1962). Acute edema in leprosy. Int. J. Le pr. 30, 387. 